Teoria e prática

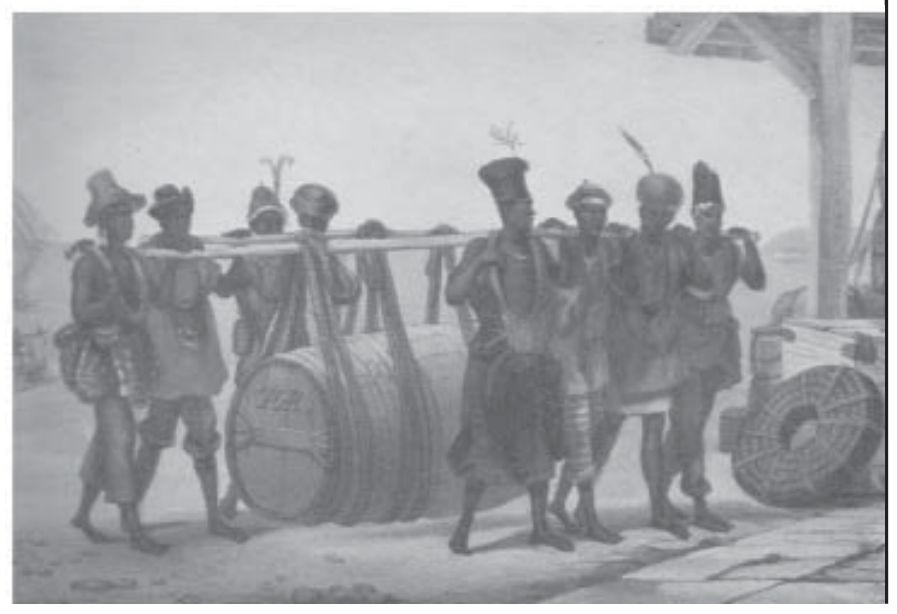




\title{
Projetos profissionais de jovens universitários/as que residem no meio rural: estudo de caso dos/as jovens do município de Meleiro, $\mathrm{SC}^{1}$
}

Projects for young professionals university students residing in rural areas: a case study of the youth of the city of Meleiro, SC

Projets pour les professionnels du collège jeunes residant dans les zones rurales: étude de cas du/de la jeunesse de la ville de Meleiro, SC

Proyectos para el colegio de profesionales de la joven que residen en las zonas rurales: un estudio de caso de/la juventud de la ciudad de Meleiro, SC

\author{
Daiana Panciera Casagrande* \\ Giovana Ilka Jacinto Salvaro** \\ Dimas de Oliveira Estevam***
}

Recebido em 27/4/2011; revisado e aprovado em 30/11/2011; aceito em 20/2/2012

\begin{abstract}
Resumo: A pesquisa originária do presente artigo buscou descrever os projetos profissionais de jovens universitários que residem no meio rural do município de Meleiro, SC, e foi realizada no segundo semestre de 2011. Os sujeitos do estudo foram 23 universitários ( 16 moças e sete moços) que se deslocam de ônibus diariamente do município de Meleiro para estudar em faculdades/universidades da região de Criciúma, SC. O questionário, autoaplicável e anônimo, foi utilizado como procedimento de coleta de dados, e a análise foi desenvolvida por meio das abordagens quantitativa e qualitativa. No processo de análise dos dados, entre outras questões, foi possível constatar a busca por projetos profissionais que não incluem a permanência no meio rural.
\end{abstract}

Palavras-chave: Agricultura familiar. Juventude rural. Projetos profissionais.

Abstract: The original of this research paper aims to describe the professional projects of university students who live in rural areas of the city of Meleiro, SC and was held in the second half of 2011. The study subjects were 23 students (16 women and seven men) moving bus daily Meleiro City to study at colleges/universities in the region of Criciúma, SC. The questionnaire, self-administered and anonymous, was used as a procedure of data collection and analysis was conducted by means of quantitative and qualitative approaches. In the process of data analysis, among other issues, we could see the search for professional projects that do not include staying in rural area.

Key words: Family farm. Rural youth. Professional projects.

Résumé: L'original de ce document de recherche vise à décrire les projets professionnels des étudiants universitaires qui vivent dans les zones rurales de la ville de Meleiro, SC et a eu lieu dans la seconde moitié de 2011. Les sujets de l'étude étaient de 23 universités (16 femmes et sept hommes) se déplaçant de bus quotidien Meleiro City pour étudier dans les collèges et universités de la région Criciúma, SC. Le questionnaire, auto-administré et anonyme, a été utilisé comme une procédure de collecte des données et l'analyse a été réalisée au moyen d'approches quantitatives et qualitatives. Dans le processus d'analyse des données, entre autres questions, nous avons pu voir la recherche de projets professionnels qui ne comprennent pas rester dans les zones rurales.

Mots-clés: La ferme familiale. Les jeunes ruraux. Projets professionnels.

Resumen: El original del presente trabajo de investigación tiene como objetivo describir los proyectos profesionales de los estudiantes universitarios que viven en las zonas rurales de la ciudad de Meleiro, SC y se llevó a cabo en el segundo semestre de 2011. Los sujetos del estudio eran 23 universitarios (16 mujeres y siete hombres) que se mueve la ciudad de Meleiro diario de autobús a estudiar en colegios y universidades de la región de Criciúma, SC. El cuestionario, autoadministrado y anónimo, fue utilizado como un procedimiento de recopilación de datos y el análisis se llevó a cabo a través de enfoques cuantitativos y cualitativos. En el proceso de análisis de datos, entre otras cuestiones, pudimos ver la búsqueda de proyectos profesionales que no incluyen permanecer en las zonas rurales. Palabras clave: Granja de la familia. La juventud rural. Proyectos profesionales.

\footnotetext{
* Graduada em Economia pela Universidade do Extremo Sul Catarinense (UNESC).

E-mail: daianacasagrande@yahoo.com.br

** Doutora em Ciências Humanas pela Universidade Federal de Santa Catarina (UFSC). Graduada em Psicologia. Professora da Unidade de Ciências Sociais Aplicadas da UNESC e do Curso de Psicologia do Centro Universitário Barriga Verde (UNIBAVE). E-mail: giovanailka@gmail.com

*** Doutor em Sociologia Política pela UFSC. Graduado em Economia. Professor do Departamento de Economia da UNESC. E-mail: doe@unesc.net

${ }^{1}$ Esse artigo apresenta a síntese dos resultados de um Trabalho de Conclusão do Curso de Graduação em Economia, da Universidade do Extremo Sul Catarinense (UNESC), realizado pela acadêmica Daiana Panciera Casagrande, no ano de 2011
} 


\section{Introdução}

A pesquisa originária do presente artigo buscou descrever os projetos profissionais de jovens universitários/as que residem no meio rural do Município de Meleiro,SC, e teve como objetivos específicos: apresentar características socioeconômicas do município de Meleiro,SC; identificar quantos integrantes da família dos/as jovens residem na propriedade rural; verificar quais são as atividades agrícolas desenvolvidas pela família do/a jovem; caracterizar a renda econômica mensal dos/as jovens e de sua família; verificar se os/as jovens desenvolvem atividades agrícolas na propriedade rural e/ou atividades não agrícolas; identificar quais são os cursos universitários escolhidos pelos/as jovens; identificar se os projetos profissionais dos/ as jovens incluem a permanência ou não no meio rural, no sentido de residência e de desenvolvimento de atividades profissionais; examinar se há diferenças entre os projetos profissionais de homens e mulheres.

As categorias centrais de análise foram agricultura familiar, juventude rural e projetos profissionais. Para Wanderley (2001, p. 23), "o ponto de partida é o conceito de agricultura familiar, entendida como aquela em que a família, ao mesmo tempo em que é proprietária dos meios de produção, assume o trabalho no estabelecimento produtivo".

Esse caráter familiar é ressaltado pela autora acima, dado que o conceito não é apenas um detalhe descritivo ou superficial, mas demonstra uma estrutura produtiva que une família, produção e trabalho. Da associação entre família, produção e trabalho, é criada a expectativa de investimentos em recursos materiais e de trabalho, que serão transmitidos às gerações seguintes, no sentido de manter a sua sobrevivência (WANDERLEY, 2001). Desse modo, a autora evidencia que as estratégias de reprodução, do ponto de vista do agricultor, baseiam-se na valorização dos recursos e se destinam a assegurar a sobrevivência da família no presente e no futuro.

Quanto à definição de juventude rural, Esteves e Abramovay (2007, p. 23) ressaltam que se trata de uma construção social, ou seja, é produzida pela sociedade "a partir das múltiplas formas como ela vê os jovens, produção na qual se conjugam, entre outros fatores, estereótipos, momentos históricos, múltiplas referências, além de diferentes e diversificadas situações de classe, gênero, etnia, grupo, etc".

A juventude rural é uma categoria invisível, segundo Carneiro (1999), isto ocorre nas pesquisas acadêmicas / projetos de desenvolvimento no âmbito rural. A autora ressalta a dificuldade em delimitar com rigor tal categoria demográfica. Em discussão sobre o tema, Carneiro (1999, p. 98) interessa-se pelo modo como a juventude é afetada por mudanças ocorridas no mundo rural e observa que, grosso modo, "o jovem é um indivíduo que se encontraria em uma fase caracterizada pela discrepância entre o projeto de vida vislumbrado e as atividades em realização".

Em estudo sobre juventude rural e agricultura familiar, Ferreira e Alves (2009, p. 246) definem juventude rural como "a população residente na zonal rural e inserida na faixa etária de 15 a 29 anos". Por conta de papéis que são atribuídos aos jovens rurais, Ferreira e Alves (2009, p. 246) observam também que a juventude rural é vista como "uma categoriachave para a reprodução do campo e da agricultura familiar". Os projetos profissionais de jovens rurais, então, apresentam-se como uma questão importante em estudos sobre a temática agricultura familiar, tendo em vista o papel que ocupam na reprodução ou extinção da agricultura familiar.

De acordo com alguns estudos (SILVESTRO et al., 2001; SOMARIVA, 2010; STROPASOLAS, 2006), é possível observar que as mudanças no campo, que vêm ocorrendo nos últimos anos, têm influenciado na saída do jovem do meio rural para a cidade. Os motivos que influenciaram o/a jovem a abandonar sua terra, casa, lavouras, a vida no campo, para ir embora para a cidade, são numerosos. Entre esses motivos, podem-se citar os altos custos de produção, o preço de venda dos produtos estarem muito abaixo do esperado pela agricultura, a escassez de oportunidades aos/as jovens e de políticas públicas para incentivar a permanência no meio rural.

Vale ressaltar, ainda, que o fato de o/a jovem trabalhar com seus familiares em atividades agropecuárias pode também influenciar no êxodo rural. Contemporaneamente, as famílias são menores, o que possibilita apenas o cultivo de pequenas propriedades, 
pois não existe o número de pessoas para esse trabalho. Além disso, a geração de renda nessas pequenas propriedades pode não ser suficiente para manter, financeiramente, $\mathrm{o} / \mathrm{a}$ jovem, na agricultura dignamente.

\section{Procedimentos metodológicos}

A pesquisa foi descritiva, pois se buscou descrever "características de determinada população ou fenômeno ou o estabelecimento de relações variáveis [...]" (GIL, 2010, p. 28).

A população da pesquisa foi composta por jovens universitários/as que residem no meio rural do município de Meleiro, SC. Especificamente, a amostra foi constituída por 23 jovens universitários/as (16 moças e sete moços) com idades entre 18 e 29 anos, que se deslocam diariamente, por meio de transporte rodoviário coletivo (são duas lotações, com aproximadamente 60 jovens), para estudar em faculdades e universidades da região de Criciúma, a uma distância de 30 quilômetros. A amostragem foi por acessibilidade ou por conveniência:

[...] o pesquisador seleciona os elementos que tem acesso, admitindo que possam, de alguma forma, representar o universo [...] aplica-se este tipo de amostragem em estudos exploratórios ou qualitativos, onde não é requerido elevado nível de precisão. (GIL, 2010, p. 94).

A coleta de dados foi realizada por meio do questionário, autoaplicável e anônimo, constituído por questões fechadas e abertas. Conforme orienta Gil (2010), nas questões fechadas, foi apresentado ao respondente um conjunto de alternativas de resposta e, nas abertas, após cada pergunta, deixou-se um espaço em branco para a resposta. No processo de análise, foram utilizadas as abordagens quantitativa e qualitativa. A pesquisa quantitativa considera que tudo pode ser quantificável, o que significa traduzir em números opiniões e informações para classificá-los e analisá-los (TAFNER; SILVA; WEIDUSCHAT, 2007, p. 124). A abordagem qualitativa, conforme Richardson (1999, p. 91), "pode ser caracterizada como a tentativa de uma compreensão detalhada dos significados e características situacionais apresentadas pelos" sujeitos da pesquisa. Além de tais procedimentos metodológicos, por meio de pesquisa em bases de dados do Instituto Brasileiro de Geografia e Estatística (IBGE), buscou-se apresentar uma breve caracterização socioeconômica do município do município estudado.

\section{Breve caracterização socioeconômica do município de Meleiro, SC}

Conforme dados da Prefeitura Municipal de Meleiro ${ }^{1}$, o município está localizado no extremo sul catarinense entre a Serra e o Mar, com extensão territorial de 186.619 km², A tabela que segue apresenta a população residente urbana e rural do município no período de 1991-2010.

Tabela 1 - População Residente rural e urbana de Meleiro no período de 1991 a 2010.

\begin{tabular}{c|c|c|c}
\hline Ano & Urbana & Rural & Total \\
\hline 1991 & 3.047 & 6.708 & 9.755 \\
\hline 1996 & 2.676 & 4.302 & 6.978 \\
\hline 2000 & 3.207 & 3.873 & 7.080 \\
\hline 2010 & 3.649 & 3.351 & 7.000 \\
\hline
\end{tabular}

Fonte: IBGE - Censos Demográficos (1991, 1996, 2000 e 2010).

Pode-se notar na tabela 1 que, nos anos de 1991 a 2010, ocorreu uma diminuição de habitantes no município de Meleiro, além de ser grande a diferença entre perímetro urbano e rural. Os dados mostram também que, de 1991 a 2000, a população rural se encontra em maior proporção, porém, no ano de 2010, ocorre o inverso, tornando a população urbana maior. Mas é importante considerar que a diminuição da população em 1991 se deve à emancipação de Morro Grande.

No que diz respeito à população residente por sexo, no ano de 2010, observa-se:

Tabela 2 - população residente por sexo no ano de 2010.

\begin{tabular}{c|c|c|c}
\cline { 2 - 4 } & $\begin{array}{c}\text { Sexo } \\
\text { masculino }\end{array}$ & $\begin{array}{c}\text { Sexo } \\
\text { feminino }\end{array}$ & Total \\
\hline Área rural & 1.698 & 1.653 & 3.351 \\
\hline Área urbana & 1.760 & 1.889 & 3.649 \\
\hline
\end{tabular}

Fonte: IBGE - Censo Demográfico (2010).

${ }^{1}$ Prefeitura Municipal de Meleiro. Disponível em: <http://www.meleiro.sc.gov.br>. Acesso em: 30 set. 2011. 
Conforme o Censo Demográfico do IBGE, no ano de 2010, são sete mil pessoas residentes no município de Meleiro; 3.649 residem no meio urbano, e 3.351, no meio rural. Na tabela da população residente, observa-se que, na área rural, são 1.698 homens e 1.653 mulheres; já na área urbana, 1.760 homens e 1.889 mulheres. Verifica-se que a população feminina é maior na área urbana, enquanto que, na área rural, a população masculina é maior. Os jovens do sexo masculino, com idades entre 15 e 29 anos, somam um total de 909; já do sexo feminino, com a mesma idade, somam 932 jovens, totalizando, assim, 1.841 jovens, sendo da área urbana e rural.

Na área de educação, o município de Meleiro possui um dos mais baixos índices de evasão escolar do país, de apenas $5 \%$, conforme observa Glück (2007). De acordo com o Censo 2010 (IBGE), os dados mostram que o município conta com uma escola pública estadual, três escolas públicas municipais e seis escolas de ensino pré-escolar, que são escolas públicas municipais. No ensino fundamental, são 915 matrículas; no ensino médio, 289; e no pré-escolar, são 149 matriculados.

A base econômica do município de Meleiro é a agricultura, especialmente, no que diz respeito ao cultivo de arroz, fumo, milho, feijão e extrativismo vegetal. Conforme dados do Censo Agropecuário de 2006 (IBGE), os produtos da lavoura do município de Meleiro são distribuídos em lavoura permanente e temporária. Na lavoura permanente, observa-se a produção de banana, com uma área de estabelecimentos agropecuários de plantação de 75 hectares, sendo uma quantia pequena se for comparada com a produção de lavoura temporária. Na lavoura temporária, são colhidos cana de açúcar, feijão, fumo, arroz e mandioca. A área total dos estabelecimentos agropecuários de lavoura temporária é de 11.346 hectares.

Nas produções agrícolas de cereais, leguminosas e oleaginosas, como mostra o IBGE (2007), a maior produção é de arroz com uma quantidade plantada de 70.500 toneladas, cultivado em uma área de 9.400 hectares. Logo em seguida, vem o milho, com uma produção de 6.380 toneladas, com 1.300 hectares cultivados, e o feijão, com uma produção de 305 toneladas, produzidos em 305 hectares. Os dados mostram que o arroz é o produto mais cultivado em Meleiro, movimentando uma porcentagem grande da economia do município. Mas também se pode ver, pelos dados mencionados, que o feijão é produzido em menor quantidade que o milho, porém, em valor real, proporciona maior remuneração.

O Censo agropecuário (IBGE, 2006) mostra que o município de Meleiro possui 848 unidades de estabelecimentos agropecuários, em um total de 14.418 hectares em áreas de estabelecimentos agropecuários. Esse número de estabelecimentos agropecuários, com arrendatários, é de 132 unidades. As áreas com matas e/ou florestas naturais, que são destinadas à preservação permanente ou reserva legal, são de 63 unidades, com um total de área dos estabelecimentos agropecuários de 254 hectares. O município possui 520 unidades de tratores, nos estabelecimentos agropecuários, dos quais apenas 367 possuem esses maquinários. Os dados revelam que não são todos os estabelecimentos que possuem maquinários. Porém, de acordo com os dados (520 unidades para 367 estabelecimentos), verifica-se que existe mais de um maquinário por estabelecimento.

Conforme dados do SEBRAE (2010), o PIB (per capita) do Município de Meleiro em relação ao Estado de SC e do Brasil era, em 2002, de R\$9.342,79; já em 2006, esse índice acumulava $\mathrm{R} \$ 13.519,09$, o que resultou em um acúmulo de $44,7 \%$.

\section{Juventude rural e o (des)interesse pela agricultura familiar: projetos profissionais em análise}

A análise que segue foi organizada a partir da distribuição dos jovens por sexo, idade, cursos e fases dos cursos de graduação, estado civil, local de domicílio, área de terra da família, número de pessoas que residem no domicílio dos/as universitários/as, atividades agropecuárias realizadas pela família destes, participação dos jovens nas atividades agrícolas realizadas pela família, acesso deles à renda das atividades agropecuárias realizadas pela sua família, atividades não agrícolas desenvolvidas por eles, pretensão relativa a projeto profissional, dificuldades identificadas para se estabelecerem profissionalmente como agricultor/a e acesso à terra.

No que diz respeito à distribuição dos envolvidos quanto ao sexo, o feminino retrata 
$70 \%$ da população pesquisada e o masculino $30 \%$. Os dados sugerem que o meio rural pode não fornecer ao grupo feminino tanta relevância quanto oferece ao masculino. $\mathrm{Na}$ agricultura, como mostra Stropassolas (2006), que realizou pesquisa sobre a temática da juventude rural em um município do meio oeste catarinense, a mulher sempre foi excluída das heranças familiares e a elas não caberiam herdar terras, pois acabariam construindo outra família. Apesar dessa realidade, transformada por meio de direitos sociais adquiridos, o contexto ainda se revela bastante desfavorável à permanência da mulher no campo.

$\mathrm{Na}$ distribuição dos/das jovens por idade, $70 \%$ desses universitários têm entre 18 e 20 anos; de 21 a 23 anos são $17 \%$; de 24 a 26 anos são 13\%. A tabela abaixo apresenta a distribuição dos jovens pesquisados por cursos de graduação.

Tabela 3 - Distribuição dos/as universitários/as por cursos de graduação

\begin{tabular}{l|c|c}
\hline Distribuição dos/as universitários/as por cursos de graduação & n. de universitários/as & $\%$ \\
\hline Ciências Contábeis & 11 & 48 \\
\hline Tecnologia em Gestão de Recursos Humanos & 2 & 9 \\
\hline Jornalismo & 1 & 5 \\
\hline Educação Física & 1 & 5 \\
\hline Comunicação Social & 1 & 5 \\
\hline Direito & 1 & 4 \\
\hline Matemática & 1 & 4 \\
\hline Secretariado Executivo & 1 & 4 \\
\hline Ciência da Computação & 1 & 4 \\
\hline Engenharia Civil & 1 & 4 \\
\hline Gestão Comercial & 1 & 4 \\
\hline Total & 23 & 100 \\
\hline
\end{tabular}

Fonte: Do autor (2011).

A tabela 3 mostra que, entre os cursos mais procurados, está o curso de Ciências Contábeis com $48 \%$; o de tecnologia de recursos humanos com $9 \%$; na sequência, observam-se os cursos de jornalismo, educação física e comunicação social com $5 \%$ e, com $4 \%$, os cursos de direito, matemática, secretariado executivo, ciência da computação, engenharia civil e gestão comercial. Quantos às fases dos cursos de graduação, da 1aa à $3^{\underline{a}}$ fase são $39 \%$ dos universitários; a mesma porcentagem é percebida entre a $4^{\mathrm{a}}$ e $6^{\mathrm{a}}$ fase; e da $7^{\mathrm{a}}$ à $9^{\mathrm{a}}$ fase ocorre uma diminuição de $22 \%$.

Sobre o estado civil, $96 \%$ dos jovens universitários/as são solteiros, e apenas $4 \%$ são casados. Os/as jovens declararam também não ter filhos/as. Conforme os dados coletados, $87 \%$ dos jovens residem com sua família e $13 \%$ não. No grupo pesquisado, $96 \%$ responderam que a família reside em área própria, e $4 \%$, que não residem em área própria. De acordo com Stropassolas (2006, p. 133), "diferentemente de outras categorias sociais, o agricultor (a) é ou procura ser, de maneira geral, proprietário (a) da terra, dono (a) dos meios de produção, trabalhador (a); e chefe de família [...]". Nesse sentido, ter sua própria terra é um dos objetivos do agricultor(a), bem como ser dono(a) de seu próprio chão e trabalhar para esse objetivo.

No que se refere à quantidade de área de terra da família dos/as universitários/as, $26 \%$ dos jovens declararam possuir uma área de $300 \mathrm{~m}^{2}$ a 10 hectares; $9 \%$ dizem possuir de 11 hectares a 20 hectares; de 21 hectares a 50 hectares também representa 9\% dos entrevistados; e acima de 50 hectares, apenas um. Porém é importante considerar que 52\% não responderam à questão. Ressalta-se ainda que a quantidade de área de terra apresentada foi organizada a partir das respostas dos sujeitos pesquisados. 
Quanto ao número de pessoas que residem no domicílio dos/as universitários/as, evidencia-se que de 1 a 3 pessoas são $31 \%$; de 2 a 6 pessoas $65 \%$; e de 7 a 9 pessoas apenas $4 \%$. Nesse sentido, cabe fazer referência ao estudo de Stropassolas (2006, p. 140) para evidenciar que o "padrão cultural pautado na existência de famílias com grande número de filhos (as) muda radicalmente nos dias atuais [...]". Sobre essa mudança, Stropassolas (2006, p. 140) destaca um aspecto que parece central: "a resistência (muitas vezes silenciosa) das mulheres às normas estabelecidas pela Igreja $^{2}$ desempenha um papel muito importante nesse processo, ilustrando a ocorrência de mudanças culturais no espaço rural, de maneira geral, e na instituição família, em particular".

A tabela 4 apresenta as atividades agropecuárias realizadas pela família dos/ as jovens pesquisados/as.

Tabela 4 - Atividades agropecuárias realizadas pela família dos/as jovens pesquisados

\begin{tabular}{l|c|c}
\hline Tipo de atividade & $\begin{array}{c}\text { N. de } \\
\text { universitários/as }\end{array}$ & $\%$ \\
\hline Cultivo de Arroz & 20 & 54 \\
\hline Cultivo de milho & 6 & 16 \\
\hline Cultivo de fumo & 5 & 14 \\
\hline Cultivo de feijão & 2 & 5 \\
\hline Pecuária & 2 & 5 \\
\hline Não responderam & 2 & 6 \\
\hline
\end{tabular}

Fonte: Do autor (2011).

Conforme a tabela 4 mostra, $54 \%$ das famílias cultivam arroz, seguindo com $16 \%$ no cultivo de milho. O fumo é cultivado por $14 \%$, a pecuária e o cultivo de feijão são $5 \%$. Não responderam à questão $6 \%$ dos participantes. É importante destacar que os respondentes optaram por mais de uma atividade. Há situações, como a revelada na pesquisa, em que a agricultura diversificada é substituída pela monocultura - no caso da pesquisa, o cultivo do arroz, que aparece em $54 \%$ dos pesquisados. Entre outros aspectos, o arroz

\footnotetext{
2 Especificamente, Stropassolas (2006, p. 140) se refere ao papel da Igreja na manutenção de certa taxa de natalidade: "os padres apelavam às famílias que acolhessem com alegria todos os filhos, porque eles são 'uma benção de Deus".
}

acabou por se tornar monocultivo na região devido ao fato de o produto ser o mais bem adaptado à região. $\mathrm{O}$ monocultivo, muitas vezes, causa a falta de oportunidades, como revela Olinger (1991, p. 78), quando diz que "o pequeno agricultor, sempre que possível e conveniente, deverá diversificar suas atividades [...]"; afinal a diversificação pode trazer grandes benefícios e a oportunidade de novas formas de cultivo, consequentemente, trabalho para todos os integrantes da família, inclusive, para os jovens.

Sobre a participação nas atividades agropecuárias realizadas pela família, 17\% dos jovens responderam que participam das atividades realizadas pela família na agricultura e $83 \%$ que não participam. Stropassolas (2006) evidencia que as atividades agrícolas podem ser desenvolvidas pelos jovens desde criança, de acordo com a organização de cada família. Porém nem todos assumem tal responsabilidade quando adolescentes ou mesmo em outras faixas etárias da vida. Nesse sentido, muitas são as razões que levam o jovem a não participar da atividade rural da família, como por exemplo, querer outro destino fora do meio rural ou não gostar da atividade desenvolvida pelos pais.

Apenas 9\% dos jovens responderam que têm acesso à renda das atividades agropecuárias realizadas pela família, e 91\% que não. Pode-se perceber que a maioria dos jovens universitários não tem acesso à renda familiar, e foram poucos os que responderam conclusivamente, sendo que a resposta foi "depende". No estudo realizado por Coradini (2008) acerca dos projetos profissionais das jovens na agricultura familiar do Rio Grande do Sul, observa-se que estas possuem acesso à renda familiar quando solicitam aos pais e, em pouquíssimos casos, recebem alguma quantia periodicamente. $\mathrm{O}$ autor menciona que são poucos os acessos a linhas de créditos como o Programa Nacional de Fortalecimento da Agricultura Familiar (PRONAF) para jovens, e a grande maioria nem conhece esses programas de crédito para jovens agricultores.

Verifica-se que $57 \%$ dos questionados responderam que não desenvolvem outra atividade, e $43 \%$, que realizam atividades não agropecuárias. Stropassolas (2006) ressalta que os reflexos dos descontentamentos dos/ as filhos/as se manifestam no movimento 
dos/as jovens em busca de oportunidades de trabalho ou mesmo acesso a níveis superiores de educação.

Quanto à renda mensal de todas as pessoas que moram no domicílio dos/as jovens pesquisados/as, um total de $22 \%$ está na faixa de $\mathrm{R} \$$ 850,00 a $\mathrm{R} \$ 1.500,00$; de $\mathrm{R} \$ 1.501,00$ a
$\mathrm{R} \$ 2.500,00$ é uma porcentagem maior, com $35 \%$ dos entrevistados; já de $\mathrm{R} \$ 2.501,00$ a R\$5.000,00 são 17\%; e os jovens universitários que não responderam à questão foram $26 \%$.

A tabela 5 apresenta os projetos profissionais pretendidos pelos jovens universitários.

Tabela 5 - Projeto profissional pretendido pelos universitários (sexo masculino)

\begin{tabular}{l|c|c}
\multicolumn{1}{c|}{ Respostas } & N. de universitários & $\%$ \\
\hline A) Estabelecer-se profissionalmente como agricultor(a). & 1 & 14 \\
\hline $\begin{array}{l}\text { B) Permanecer no meio rural, realizando atividades agrícolas em } \\
\text { tempo parcial. }\end{array}$ & 0 & 0 \\
\hline $\begin{array}{l}\text { C) Permanecer no meio rural, realizando atividades profissionais } \\
\text { não agrícolas. }\end{array}$ & 1 & 0 \\
\hline $\begin{array}{l}\text { D) Trabalhar na área de formação universitária e permanecer no } \\
\text { meio rural. }\end{array}$ & 5 & 72 \\
\hline $\begin{array}{l}\text { E) Trabalhar na área de formação universitária e morar no meio } \\
\text { urbano. }\end{array}$ & 7 & 100 \\
\hline Total & & \\
\hline
\end{tabular}

Fonte: Do autor (2011).

Quanto ao futuro profissional, os jovens do sexo masculino revelaram que apenas $14 \%$ pretendem se estabelecer profissionalmente como agricultores; outros 14\% irão trabalhar na área de formação universitária, mas permanecer no meio rural; e a grande maioria, $72 \%$ dos jovens universitários, optou pela resposta trabalhar na área de formação universitária e morar no meio urbano.

Stropassolas (2006, p. 296) traz uma questão bastante relevante, quando diz que “[...] os jovens que saem para estudar dificilmente voltam [...]". São jovens que buscam alternativas de trabalho fora do meio rural, ou mesmo que não gostam do trabalho, pois almejam outras atividades para sua vida. $\mathrm{O}$ autor observa que

[...] o estudo passa a ser a preparação para o trabalho urbano [...] é visto por alguns pais como possibilidade e esperança de uma melhor remuneração da força de trabalho de seus filhos, inclusive como confiança de que poderão ser amparados por eles em sua velhice. (STROPASSOLAS, 2006, p. 302).
Contudo Stropassolas (2006, p. 306) também verificou que os depoimentos de alguns filhos de agricultores sugerem o acesso à educação como uma forma que

[...] permite a sua maior qualificação profissional para o exercício eficiente do gerenciamento das atividades produtivas, bem como o acesso à independência financeira que o maior nível educacional propicia e, assim, investir na agricultura ou na satisfação de suas necessidades de consumo.

No que diz respeito ao futuro profissional dos rapazes como agricultores, Silvestro et al (2001, p. 45), na pesquisa que realizaram no oeste catarinense sobre o tema sucessão hereditária na agricultura familiar, verificaram que "a aspiração por viver na cidade é tanto maior quanto menos promissor o horizonte de geração de renda no estabelecimento paterno".

A tabela 6 apresenta os projetos profissionais pretendidos pelas jovens universitárias. 
Tabela 6 - Projeto profissional pretendido pelas universitárias (sexo feminino)

\begin{tabular}{l|c|c}
\multicolumn{1}{c|}{ Respostas } & N. de universitárias & $\%$ \\
\hline A) Estabelecer-se profissionalmente como agricultor(a). & 0 & 0 \\
\hline $\begin{array}{l}\text { B) Permanecer no meio rural, realizando atividades agrícolas } \\
\text { em tempo parcial. }\end{array}$ & 0 & 0 \\
\hline $\begin{array}{l}\text { C) Permanecer no meio rural, realizando atividades } \\
\text { profissionais não agrícolas. }\end{array}$ & 1 & 6 \\
\hline $\begin{array}{l}\text { D) Trabalhar na área de formação universitária e permanecer no } \\
\text { meio rural. }\end{array}$ & 3 & 19 \\
\hline $\begin{array}{l}\text { E) Trabalhar na área de formação universitária e morar no meio } \\
\text { urbano. }\end{array}$ & 11 & 69 \\
\hline F) Outros & 1 & 100 \\
\hline Total & 16 & 6 \\
\hline
\end{tabular}

Fonte: Do autor (2011).

De acordo com a tabela 6, em que se apresentam dados acerca do projeto profissional pretendido pelas universitárias, não se observa diferença em relação aos jovens universitários, pois $6 \%$ delas optam por permanecer no meio rural, realizando atividades profissionais não agrícolas; $19 \%$ querem trabalhar na área de formação universitária, mas permanecer no meio rural; e $69 \%$, como constatado também nas respostas dos universitários, desejam trabalhar na área de formação universitária, porém morar no meio urbano; e para outras opções foram $6 \%$ das universitárias.

Como se observa, as universitárias não pretendem se estabelecer como agricultoras. Comparando com a distribuição dos/as universitários pelo sexo, pode-se notar que o sexo feminino retrata $70 \%$ da população pesquisada. Sobre tal aspecto cabe fazer menção à pesquisa de Silvestro et al (2001, p. 46), na medida em que verificou, entre as moças, "à rejeição majoritária da profissão agropecuária corresponde maior esperança na inserção urbana".

Por outro lado, Goulart e Gehlen (2008) mostram que um tema do Microba- cias 2 é a "busca pela valorização das mulheres agricultoras no contexto social em que estão inseridas". Esse tema mostra que a participação das mulheres em atividades agrícolas, a partir do projeto citado, poderia trazer mais renda, satisfação no ambiente em que vivem e protagonismo financeiro; logo, o interesse das jovens por atividades agrícolas e, como consequência, a diminuição da evasão rural.

Os mesmos autores mostram alguns objetivos em relação a tal situação: a) despertar a importância do papel da mulher agricultora, nas propriedades rurais e no seu meio social; b) incentivar as agricultoras a exercitar sua liderança, assumindo cargos em diretorias, associações e pleitos eletivos; c) obter maior participação das agricultoras em encontros, oficinas, cursos e excursões; d) formar lideranças femininas para atuarem em vários segmentos sociais; e) capacitá-las, por meio de cursos e oficinas, para o exercício de novas atividades rurais.

A tabela 7 mostra as dificuldades identificadas pelos/as universitários/as para se estabelecerem profissionalmente como agricultor/a. 
Tabela 7 - Dificuldades identificadas pelos/as universitários/as para se estabelecerem profissionalmente como agricultor/a

\begin{tabular}{l|c|c}
\multicolumn{1}{c|}{ Tipos de dificuldades } & N. de universitários/as & $\%$ \\
\hline Não veem dificuldade & 4 & 18 \\
\hline Não responderam & 2 & 9 \\
\hline Preço do arroz & 4 & 18 \\
\hline Remuneração baixa & 2 & 9 \\
\hline Falta de mão de obra & 1 & 4 \\
\hline Desvalorização da profissão & 2 & 9 \\
\hline Falta de incentivo do governo & 2 & 9 \\
\hline Reconhecimento & 1 & 4 \\
\hline Horário de trabalho & 1 & 5 \\
\hline Falta de salário mensal & 1 & 5 \\
\hline Pelo fato de ser mulher & 1 & 5 \\
\hline Instabilidade financeira & 1 & 5 \\
\hline Competitividade da agricultura familiar e a empresarial & 1 & 5 \\
\hline Total & 23 & 100 \\
\hline
\end{tabular}

Fonte: Do autor (2011).

Na tabela acima, 18\% dos/as jovens não veem dificuldades para se estabelecerem profissionalmente como agricultores/as; já $9 \%$ não responderam. Para $18 \%$, a dificuldade está no preço do arroz; no entanto $9 \%$ dizem ser pela remuneração baixa, ou pela desvalorização da profissão, ou ainda, pela falta de incentivo do governo; $5 \%$ dos universitários/ as dizem ser pelo horário de trabalho, ou pela falta de salário mensal, ou pelo fato de ser mulher, ou pela instabilidade financeira, ou pela competitividade da agricultura e da empresarial; outros $4 \%$ responderam que seria pela falta de mão de obra ou de reconhecimento.

O estudo realizado por Stropassolas (2006, p. 287) revela que

[...] as mulheres sonham mais alto [...] e ficar com a família pode significar a não concretização de seus ideais, pois [...] ficar sempre debaixo da asa do pai e da mãe não vai ter outra solução senão você casar com alguém ali da comunidade mesmo.

De acordo com a pesquisa de Silvestro et al (2001, p. 43), para muitas moças " permanecer numa unidade produtiva rural [...] é muito mais uma fatalidade do que uma opção". Especificamente, os autores se referem às moças que vivem em famílias descapitalizadas e de menor renda.
Nas respostas dos/as jovens universitários/as em análise, o que se pode notar, em maior proporção, é que o preço do arroz pode contribuir para a evasão dos/das jovens da agricultura, principalmente, porque o produto é o mais cultivado no município. De acordo com os dados acerca das atividades agropecuárias realizadas pela família na propriedade rural, $54 \%$ responderam que o cultivo do arroz é a principal atividade desenvolvida pela família. No que diz respeito à desvalorização do cultivo do arroz, evidenciada por jovens da presente pesquisa, Silva (1998) também mostra que, nos anos de 1980, ocorreu uma desvalorização dos produtos da agricultura, ao mesmo tempo em que sucedeu um aumento dos custos financeiros para obtenção de crédito rural junto aos bancos.

Para Olinger (1991), as causas da evasão rural podem ser consideradas complexas e mudam, dependendo do ponto de vista, ou também da ideologia de quem as estuda. Olinger (1991) mostra que a literatura confirma que os agricultores saem do campo porque o poder econômico precisa de mão de obra barata para os setores secundários e terciários da economia nas cidades, o que provoca a saída dos agricultores do meio rural para buscar na cidade melhores condições de 
vida. Ou como se pode observar pelas respostas da população estudada, ocorre também a desvalorização da profissão.
A tabela 8 apresenta informações acerca do acesso à terra pelos/as jovens pesquisados/as.

Tabela 8 - Acesso à terra pelos/as universitários/as

\begin{tabular}{l|c|c}
\hline \multicolumn{1}{c|}{ Acesso a terra pelos/as universitários/as } & N. de universitários/as & \% \\
\hline Acesso à terra por herança & 7 & 31 \\
\hline Não tem/terá terra & 13 & 57 \\
\hline Não responderam & 1 & 4 \\
\hline Já possui & 1 & 4 \\
\hline Outro & 1 & 4 \\
\hline Total & 23 & 100 \\
\hline
\end{tabular}

Fonte: Do autor (2011).

Conforme a tabela 8 , quanto ao acesso à terra, pelos/as universitários/as, 31\% será por meio de herança; $57 \%$ responderam que não têm ou terão terra; $4 \%$ não responderam; e $4 \%$ já possuem; já para outros $4 \%$ isso será em forma de sítio. Os dados revelam que a porcentagem que terá o acesso à terra através de herança se define como fator em $31 \%$, pois é uma modalidade de acesso bastante comum, principalmente para o sexo masculino.

Segundo Paulilo (2004, p. 233), "um fato bem conhecido, entre nós, é que o acesso das mulheres à terra é menor que o dos homens no mundo todo [...] a América Latina e, dentro dela, o Brasil não são exceções". A autora esclarece que o fato de ser um direito conquistado em vários países não significou que, concretamente, a herança vai ser partilhada igualmente entre filhas e filhos. Silvestro et al. (2001, p. 45) evidenciam que "o acesso à terra está entre as maiores dificuldades para a continuidade na agropecuária". Os autores verificaram que, em alguns casos, os pais já escolheram seu sucessor, os quais demonstram mais interesse em ficar na propriedade, os que assumiram a profissão de agricultor por objetivo. Os autores também ressaltam outro ponto interessante, em que a questão do processo sucessório, em muitos casos, gera confusões, ou seja, conflitos, os quais nascem da disputa, divisão dos valores territoriais, pois acaba por gerar a contemplação, entre os filhos, diferenciada.

\section{Considerações finais}

A pesquisa mostrou que os jovens pesquisados são a maioria do sexo feminino (70\%); com idade entre 18 e 20 anos (70\%) e solteiros (96\%). Na distribuição dos cursos de graduação, destacam-se ciências contábeis $(48 \%)$ e tecnologia em gestão de recursos humanos (9\%). E possível observar algumas questões envolvidas no processo de mudança, sejam estas diretas, como a permanência do jovem no campo, sejam indiretas, como as consequências para a agricultura do êxodo rural juvenil.

Dentre questões que puderam ser verificadas, destaca-se que grande parte dos jovens universitários do município de Meleiro (75\%) reside no meio rural, mas, para o futuro, pretendem trabalhar na área de formação universitária e viver no meio urbano. Uma quantidade menor pretende se estabelecer profissionalmente como agricultor e, conjuntamente, trabalhar na área de formação universitária. A permanência no meio rural foi uma opção pouco apresentada pelos/as jovens da pesquisa.

Quanto às jovens universitárias, observou-se que a maioria pretende trabalhar na área de formação universitária e morar no meio urbano. Sendo que outra parte menor das jovens apresentou a possibilidade de trabalhar na formação universitária e permanecer no meio rural, enquanto que uma pequena 
parcela diz querer permanecer no meio rural, realizando atividades não agrícolas. Um dos fatores que pode ser destacado para corroborar tal quadro na agricultura é a forma de acesso à terra. São poucos os jovens que têm acesso à terra e os que terão será por herança, o que acaba por se tornar uma incerteza na vida futura, principalmente, para permanecer na agricultura.

Este estudo mostrou ainda dificuldades encontradas na agricultura, tanto econômicas (preço do produto final, recursos para se manter) quanto sociais (principalmente a questão relacionada à cultura do ser agricultor), pois a sua compreensão depende de muitos fatores. Além disso, é preciso compreender as relações estabelecidas entre os/as jovens, o meio rural e o urbano, bem como o que envolve o meio econômico na agricultura, como a renda familiar, o sustento da família na agricultura. A pesquisa revelou a possibilidade de êxodo rural de jovens no município, pois os projetos profissionais pretendidos não incluem a permanência na agricultura, seja por falta de incentivo, por falta de renda, educação, entre outras oportunidades que a agricultura, ainda, não consegue propiciar aos jovens.

\section{Referências}

CARNEIRO, Maria José. O ideal urbano: a relação campo e cidade no imaginário de jovens rurais. In: TEIXEIRA DA SILVA, F. C.; SANTOS, R.; COSTA, L. F. C. (Orgs.). Mundo rural e política: ensaios interdisciplinares. Rio de Janeiro. Campus: Promex, 1999, p. 97-115.

CORADINI, Lucas. Autonomia e Projetos Profissionais das Jovens na Agricultura Familiar do Rio Grande do Sul. In: BRASIL - Presidência da República. Secretaria Especial de Políticas para as Mulheres. 3ํ Prêmio Construindo a Igualdade de Gênero - redações e artigos científicos vencedores. Brasília, 2008. p. 176-188.

ESTEVES, Luiz Carlos Gil; ABRAMOVAY, Miriam. Juventude, pelos outros e por elas mesmas. In: ESTEVES, Luiz Carlos Gil; ABRAMOVAY, Miriam; ANDRADE, Eliane Ribeiro. Juventude: outros olhares sobre a diversidade. Brasília: Ministério da Educação, Secretaria de Educação Continuada, Alfabetização e Diversidade; Unesco, 2007. p. 21-56.

FERREIRA, Brancolina; ALVES, Fábio. Juventude rural: alguns impasses e sua importância para a agricultura familiar. In: CASTRO, Jorge Abrahão de; AQUINO, Luseni Maria C. de; ANDADRE, Carla Coelho de. (Orgs.). Juventude e políticas sociais no Brasil. Brasília: IPEA, 2009. p. 245-257.
GIL, Antônio Carlos. Métodos e técnicas de pesquisa social. 6. ed. São Paulo: Atlas, 2010.

GLÜCK, Renê. Perfil cultural e turístico dos municípios catarinenses: município de Meleiro. Forquilhinha, SC: Glück Edições, 2007.

GOULART, Evando Quirino; GEHLEN, Joel. Tifa Esperança: uma abordagem socioeconômica e ambiental do Projeto Microbacias 2, no Norte Catarinense. Joinvile/ SC: Letra Dágua, 2008.

INSTITUTO BRASILEIRO DE GEOGRAFIA E ESTATÍSTICA (IBGE). Censo 2010. Disponível em: <www. ibge.gov.br/home/>. Acesso em: 10 set. 2011.

Censo 2000. Disponível em: <www.sidra.ibge. gov.br>. Acesso em: 10 set. 2011.

Censo 1996. Disponível em: <www.sidra.ibge. gov.br>. Acesso em: 10 set. 2011.

Censo 1991. Disponível em: <www.sidra.ibge. gov.br>. Acesso em: 10 set. 2011.

. Censo agropecuário 2006. Disponível em: <http:/ / www.ibge.gov.br/cidades>. Acesso em: 10 set. 2011.

. Produção agrícola municipal - cereais, leguminosas e oleaginosas 2007. Disponível em: <http:/ / www.ibge.gov. br/cidadesat/topwindow.htm?1>. Acesso em: 3 nov. 2011.

OLINGER, Glauco. Êxodo rural: campo ou cidade? Florianópolis: ACARESC, 1991.

PAULILO, Maria Ignez S. Trabalho familiar: uma categoria esquecida de análise. Revista Estudos Feministas, Florianópolis, v. 12, n. 1, p. 229-252, jan/abr. 2004.

RICHARSON, Roberto Jarry. Pesquisa social: métodos e técnicas. 3. ed. São Paulo: Atlas,1999.

SERVIÇO DE APOIO ÀS MICRO E PEQUENAS EMPRESAS SANTA CATARINA (SEBRAE/SC). Santa Catarina em números: Meleiro. Florianópolis: SEBRAE/SC, 2010.

SILVA, José Graziano da. A nova dinâmica da agricultura brasileira. 2. ed. rev. Campinas: UNICAMP. IE, 1998.

SILVESTRO, Milton Luiz et al. Os impasses sociais da sucessão hereditária na agricultura familiar. Florianópolis: EPAGRI; Brasília: Nead/Ministério do Desenvolvimento Agrário, 2001.

SOMARIVA, Domício Filho. O campo está envelhecendo e a juventude perdendo o interesse pela atividade rural. Revista Folha Rural. Meleiro, ed. 22, julho/agosto, 2010.

STROPASOLAS, Valmir Luiz. O mundo rural no horizonte dos jovens. Florianópolis: UFSC, 2006.

TAFNER, José; SILVA, Antônio César da; WEIDUSCHAT, Íris. Caderno de Estudos: Metodologia do Trabalho Acadêmico. 2. ed. Revista e atualizada. Indaial: ASSELVI, 2007.

WANDERLEY, Maria de Nazareth Baudel. Raízes históricas do Campesinato brasileiro. In: TEDESCO, João Carlos (Org.). Agricultura familiar: realidades e perspectivas. 3. ed. Passo Fundo: UPF, 2001, p. 21-55. 